\title{
The Safe Use of Sharps and Needlestick among Nurses Working in Surgical Clinics, Turkey
}

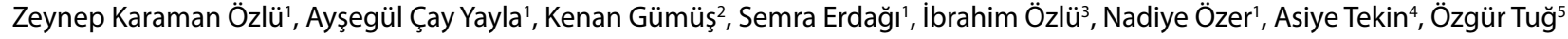 \\ 'Department of Surgical Nursing, Atatürk University School of Medicine, Erzurum, Turkey \\ 2Department of Surgical Nursing, Amasya University School of Medicine, Amasya, Turkey \\ ${ }^{3}$ Department of Emergency Medicine, Atatürk University School of Health Sciences, Erzurum, Turkey \\ ${ }^{4}$ Clinic of Surgical Nursing, Ankara Yıldırım Beyazıt Training and Research Hospital, Ankara, Turkey. \\ ${ }^{5}$ Eskişehir Osmangazi Medical School Hospital, Eskişehir, Turkey
}

\begin{abstract}
Aim: The purpose of this study was to determine the attitude of nurses working in surgical clinics regarding the safe use of sharps and towards needlestick injuries.

Materials and Methods: This cross sectional descriptive study was conducted between December 2013 and February 2014 in the surgical clinics of research hospitals located in three cities within Turkey. A 54-item questionnaire consisting of 5 categories was used as the research tool. On the questionnaire was completed by 360 surgical staff nurses who agreed to participate in the study and were not on sick leave or off duty (participation rate was $88.2 \%$ ).

Results: The mean score obtained from nurses using the Turkish version of the "scale of medical staff's attitude regarding the safe use of sharps and needlestick" questionnaire was $108.64 \pm 11.30$. It was also determined that $46.1 \%$ of the nurses were injured $1-5$ time(s) a year; $40.6 \%$ had needlestick, $32.5 \%$ were injured with broken ampoule pieces, $54.4 \%$ were vaccinated against hepatitis and tetanus; and $63.0 \%$ had knowledge about the activities of the infection control committee.

Conclusions: Because of the high level of sharps and needlestick injuries, the following can be recommended: routinely conducting serological tests of the personnel routinely, change the submission of annual assessment reports into an institutional policy, and offer in-service training programs periodically.
\end{abstract}

Keywords: Surgical clinic, sharps, needlestick, injury, nurses

\section{Introduction}

Medical services have many risk factors that adversely affect the health of hospital personnel in particular (1). In a study conducted in 2004, Sharp and needlestick injuries are the main occupational accidents and risks that medical personnel are exposed to at a rate of $80 \%$ (2).

Sharp and needlestick injuries refer to medical or laboratory materials that can cause skin penetration injuries when held. Needles, pointed intravenous intervention tools, bistouries, injectors, and broken pipette or ampoule glass pieces all belong to this category. Additionally, solid plastic materials that can cause injury are also regarded among these materials (3). The most commonly encoun- tered problems in work, in terms of infections that the medical personnel can catch, are injury through blood-contaminated sharps and needlestick or splattering of infected blood, or body fluids, on the mucosa (4).

In surgical clinics, the working safety of surgical clinic nurses can be affected by reasons such as: an insufficient number of nurses, excessive work load, working in shifts, the emotional stress resulting from of working with individuals with illness, working with patients in need of intensive care and dying patients, disagreements experienced with patients, interpersonal negative relationships, bad physical conditions, institutional policies, and the insufficiency of participation in decision making activities $(5,6)$. It has been emphasized that the rate of sharp and needlestick injuries, which is generally

This study was presented at the $19^{\text {th }}$ National Surgical Congress and $14^{\text {th }}$ Surgical Nursing Congress, 16-20 April 2014, Antalya, Turkey.

Correspondence to: Zeynep Karaman Özlü e-mail:zynp_krmnzl@hotmail.com 
$18.1 \%$ among nurses, has been at a level of $70 \%-75 \%$ among nurses working in surgical clinics such as surgery rooms and emergency units (7). In another study, it was stated that the rate of sharp and needlestick injuries was $22.8 \%$ for nurses, and they were ranked second among healthcare personnel for sharp and needlestick injuries (8). The study of Nsubuga and jaakkola (9) showed a significantly increased risk of needlestick injuries among those who were recapping needles most or all of the time compared to those who were not recapping needles. Despite the known risks, frequency of needlestick injury was generally higher especially among health professionals reflecting bad practices and careless attitudes towards work (10).

The purpose of this study was to analyze the attitudes of nurses working in surgical clinics regarding the safe use of sharps and needlestick injuries.

\section{Materials and Methods}

This descriptive study was conducted between December 2013 and February 2014 in the surgical clinics (surgery room, emergency unit, intensive care unit, orthopedics, urology, plastic and reconstructive surgery, eye diseases, otorhinolaryngology, brain surgery, cardiovascular surgery, thoracic surgery, and general surgery)of Atatürk University Medical Faculty Research Hospital (AUMRH), Ankara Yıldırım Beyazıt Training and Research Hospital (AYBH), and Eskişehir Osmangazi Medical School Hospital (EOUTFH).

The study population consisted of 408 nurses working in the surgical clinics of AUMRH, AYBH, and EOUTFH. The study had planned to include all nurses in the study population; however, a total of 360 nurses were included in the study since 22 nurses working in the surgical clinics did not agree to participate in the study and 26 were on leave (participation rate was $88.2 \%$ ). Written informed consent was obtained from the participants.

\section{Instruments}

A "socio-demographic" questionnaire, including introductory information about the nurses, was prepared in accordance with the literature and the "scale of medical staff's attitude regarding the safe use of sharps and needlestick" was used to collect data. Questions regarding the socio-demographic characteristics of nurses, clinics they worked at, frequency of sharps use, frequency of needlestick during work, and the precautions they take were given place in the questionnaire prepared by the researcher in accordance with the literature.

The validity and reliability study of the Turkish version of the "scale of medical staff's attitude regarding the safe use of sharps and needlestick" was conducted by Uzunbayır in 2009 (11). This is a Likert type scale consisting of 5 categories and 54 items that assess the opinions of attitudes of medical personnel regarding the safe use of sharps and of needlestick. The scale includes an equal number of items grouped into behavioral, affective, and cognitive attitudes. A negative ness-positive ness pattern was pursued in the placement of questions: 9behavioral positive items, 9behavioral negative items, 9 affective positive items, 9 affective negative items, 9 cognitive positive items, and 9 cognitive negative items. The scoring of the positive items was as follows: I totally agree (5 points), I agree (4 points), I am indecisive (3 points), I disagree (2 points), I totally disagree (1 point). The reactions given to the negative items are reversely scored. While the lowest score to be received from the scale is 54 , the highest score is 270. A low score received from the scale indicates the unsafe use of sharps by the medical personnel; whereas a high score indicates the safe use of sharps by the medical personnel. While the Cronbach's alpha value in the validity study was found to be 0.80 (11), the Cronbach's alpha value was 0.86 in this study.

\section{Procedure}

Data from the study were collected by the researcher during the working hours of 08:00-16:00, 16:00-24:00, or 16:00-08:00 as appropriate for nurses during their shift. A face-to-face interview method was used after nurses were informed about the purpose of the study. Verbal permission was obtained. The data collection forms were completed in about 7 minutes.

\section{Data analysis}

Data from the study were analyzed in the Statistical Package for the Social Sciences version 15.0 (SPSS Inc.; Chicago, IL, USA) program. Percentage distribution, mean, ANOVA, and t-test were used for assessing the data. Analysis of variance was used for data demonstrating normal distribution and the Kruskal-Wallis test was used for data not demonstrating a normal distribution in comparison of groups in terms of independent variables. When the difference between groups was examined, 0.05 was used as the significance level. While the value of $p<0.05$ indicated a significant difference among groups, the value of $p>0.05$ signified no significant difference among groups.

\section{Ethics}

Before starting the study, ethics committee approval was received from AUMRH for conducting the study. Afterwards, along with the approval of the ethics committee, the information form including the purpose and scope of the study was submitted to the Head Physician's Office of each Hospital and written permissions were received.

\section{Results}

Demographic characteristics of the 360 nurses included in the scope of this study are given in Table $1.44 .2 \%$ were within the age range of $26-35$ years, $84.2 \%$ were female, $48.1 \%$ held a bachelor's degree, $45.6 \%$ worked at AYBH, $41.1 \%$ had0 -5 years of total work experience, $55.6 \%$ had $0-5$ years of experience in surgical clinics, $14.7 \%$ currently worked in an emergency service unit, $46.1 \%$ had injuries 1-5 time(s) per year, and $63.0 \%$ had knowledge about the activities of the infection control committee.

When the distribution of nurses according to their occupational exposure status was assessed (Table 2), it was determined that $40.6 \%$ of nurses were injured with injector needles, $3.1 \%$ with IV catheters, $7.5 \%$ with serum set needles, $11.1 \%$ with suture needles, $32.5 \%$ with broken ampoule pieces, $0.8 \%$ with cautery, and $10.3 \%$ with lancet-bistoury. Furthermore, $26.1 \%$ were naturally immune, $18.6 \%$ were not vaccinated due to neglect, and $54.4 \%$ were vaccinated against hepatitis and tetanus.

When mean scale scores of nurses according to their descriptive characteristics were compared (Table 3), it was found that nurses in the age group of 40years and above who held a bachelor's degree, worked at $\mathrm{AYBH}$, and were in the pediatric surgery clinic had higher mean scale scores than the other groups; and the difference between the groups was statistically significant. It was also determined that female nurses had higher mean scores than male nurses, and the dif- 
Table 1. Distribution of nurses according to their descriptive characteristics

\begin{tabular}{|c|c|c|}
\hline Descriptive Characteristics & Sample Size & $\%$ \\
\hline \multicolumn{3}{|l|}{ Age Groups } \\
\hline $18-25$ years & 119 & 33.1 \\
\hline $26-35$ years & 159 & 44.2 \\
\hline $36-40$ years & 55 & 15.3 \\
\hline 41 years $\uparrow$ & 27 & 7.5 \\
\hline \multicolumn{3}{|l|}{ Gender } \\
\hline Female & 303 & 84.2 \\
\hline Male & 57 & 15.8 \\
\hline \multicolumn{3}{|l|}{ Educational Status } \\
\hline Bachelor's degree & 173 & 48.1 \\
\hline Medical vocational high school & 94 & 26.1 \\
\hline Associate degree & 70 & 19.4 \\
\hline Postgraduate & 23 & 6.4 \\
\hline \multicolumn{3}{|l|}{ Institution the nurse works in } \\
\hline AYBH & 164 & 45.6 \\
\hline EOUTFH & 120 & 33.3 \\
\hline AUMRH & 76 & 21.1 \\
\hline \multicolumn{3}{|l|}{ Years of working } \\
\hline $0-5$ years & 148 & 41.1 \\
\hline $6-11$ years & 97 & 26.9 \\
\hline $12-17$ years & 52 & 14.4 \\
\hline $18-23$ years & 32 & 8.9 \\
\hline 24 years and above & 31 & 8.6 \\
\hline \multicolumn{3}{|c|}{ Years of working in the surgical clinic } \\
\hline $0-5$ years & 200 & 55.6 \\
\hline $6-11$ years & 84 & 23.3 \\
\hline $12-17$ years & 34 & 9.4 \\
\hline $18-23$ years & 24 & 6.7 \\
\hline 24 years and above & 18 & 5.0 \\
\hline \multicolumn{3}{|c|}{ Clinic the nurse currently works in } \\
\hline Emergency service & 53 & 14.7 \\
\hline Surgery room & 51 & 14.2 \\
\hline Eye-Otorhinolaryngology & 50 & 13.9 \\
\hline General surgery & 40 & 11.1 \\
\hline Neurosurgery & 37 & 10.3 \\
\hline Orthopedics & 33 & 9.2 \\
\hline Urology & 32 & 8.9 \\
\hline Cardiovascular-thoracic surgery & 28 & 7.8 \\
\hline Pediatric surgery & 20 & 5.6 \\
\hline Plastic surgery & 16 & 4.4 \\
\hline
\end{tabular}

\begin{tabular}{|c|c|c|}
\hline \multicolumn{3}{|l|}{ Number of injuries per year } \\
\hline No injuries & 160 & 44.4 \\
\hline $1-5$ time(s) & 166 & 46.1 \\
\hline $6-11$ times & 15 & 4.2 \\
\hline 12 times and above & 19 & 5.3 \\
\hline \multicolumn{3}{|l|}{ Infection Control Committee } \\
\hline $\begin{array}{l}\text { I have knowledge about their } \\
\text { activities }\end{array}$ & 227 & 63.0 \\
\hline $\begin{array}{l}\text { I do not have knowledge about } \\
\text { their activities }\end{array}$ & 133 & 37.0 \\
\hline TOTAL & 360 & 100.0 \\
\hline
\end{tabular}

Table 2. Distribution of nurses according to their occupational exposure status

\begin{tabular}{|l|c|c|}
\hline Injury factor & $\begin{array}{c}\text { Number of } \\
\text { Injured Nurses }\end{array}$ & $\%$ \\
\hline - Injector needles & 146 & 40.6 \\
\hline - Broken ampoule pieces & 117 & 32.5 \\
\hline - Suture needle & 40 & 11.1 \\
\hline - Lancet-bistoury & 37 & 10.3 \\
\hline - Serum set needle & 27 & 7.5 \\
\hline - Inserting IV catheter & 11 & 3.1 \\
\hline - Cautery & 3 & 0.8 \\
\hline Vaccination status & Number of Nurses & \\
\hline - Vaccinated against hepatitis & 196 & 54.4 \\
\hline and tetanus & 94 & 26.1 \\
\hline - Natural immunity & 67 & 18.6 \\
\hline - Being negligent & & \\
\hline
\end{tabular}

ference between mean scores was found to be statistically significant $(p=0.32)$. Those who had been working in the surgical clinics for a period of 24 years or more had higher mean scale scores than the other groups, and the difference between the groups was not statistically significant $(p=0.98)$. Those who had injuries 12 or more times had lower mean scale scores, and the difference between the groups was statistically significant $(p=0.02)$. Nurses who had knowledge about the activities of the Infection Control Committee had lower mean scale scores compared to those who did not, and the difference between the mean scores was not statistically significant $(p=0.18)$.

The scale's Cronbach's Alpha internal consistency coefficient was0.86 in this study (Table 4).

\section{Discussion}

It has been observed that personnel tend not to report injuries, tend to not receive medical help, they do not have sufficient knowledge, or even if they have knowledge, do not take sufficient universal precautions (12). The reasons behind why nurses do not report such 
Table 3. Comparison of total mean scale scores of nurses according to their descriptive characteristics

\begin{tabular}{|c|c|c|c|}
\hline & $\mathbf{n}$ & $\begin{array}{c}\text { Mean Scores } \\
\text { Received } \\
\text { from Scale } \\
\text { X } \pm \text { SS* }\end{array}$ & Significance \\
\hline \multicolumn{4}{|l|}{ Age Groups } \\
\hline $18-25$ years & 119 & $106.72 \pm 12.44$ & \multirow{4}{*}{$\begin{array}{c}\mathrm{KWU}=3.08 \\
p=0.03\end{array}$} \\
\hline $26-35$ years & 159 & $110.32 \pm 10.63$ & \\
\hline $36-40$ years & 55 & $106.95 \pm 10.87$ & \\
\hline 40 years and above & 27 & $110.70 \pm 9.29$ & \\
\hline \multicolumn{4}{|l|}{ Gender } \\
\hline Female & 303 & $108.90 \pm 11.10$ & \multirow{2}{*}{$\begin{array}{l}t=1.82 \\
p=0.32\end{array}$} \\
\hline Male & 57 & $107.28 \pm 12.37$ & \\
\hline \multicolumn{4}{|l|}{ Educational status } \\
\hline Bachelor's degree & 173 & $110.53 \pm 9.94$ & \multirow{4}{*}{$\begin{array}{c}\mathrm{KWU}=4.51 \\
\mathrm{p}=0.00\end{array}$} \\
\hline Medical vocational high school & 94 & $105.30 \pm 12.65$ & \\
\hline Associate degree & 70 & $108.33 \pm 11.92$ & \\
\hline Postgraduate & 23 & $109.08 \pm 10.70$ & \\
\hline \multicolumn{4}{|l|}{ Institution the nurse works in } \\
\hline$* * * A Y B H$ & 164 & $110.28 \pm 0.88$ & \multirow{3}{*}{$\begin{array}{l}F=3.40 \\
p=0.04\end{array}$} \\
\hline${ }^{* *}$ EOUTFH & 120 & $107.68 \pm 1.02$ & \\
\hline * AUMRH & 76 & $106.63 \pm 1.27$ & \\
\hline \multicolumn{4}{|l|}{ Years of working } \\
\hline $0-5$ years & 148 & $107.71 \pm 11.74$ & \multirow{5}{*}{$\begin{array}{l}F=0.90 \\
p=0.46\end{array}$} \\
\hline $6-11$ years & 97 & $109.33 \pm 12.16$ & \\
\hline $12-17$ years & 52 & $107.76 \pm 11.05$ & \\
\hline $18-23$ years & 32 & $109.84 \pm 8.44$ & \\
\hline 24 years and above & 31 & $111.19 \pm 9.17$ & \\
\hline \multicolumn{4}{|c|}{ Years of working in the surgical clinic } \\
\hline $0-5$ years & 200 & $108.67 \pm 0.82$ & \multirow{5}{*}{$\begin{array}{c}\mathrm{KWU}=0.44 \\
p=0.98\end{array}$} \\
\hline $6-11$ years & 84 & $108.18 \pm 1.29$ & \\
\hline $12-17$ years & 34 & $108.35 \pm 2.04$ & \\
\hline $18-23$ years & 24 & $108.75 \pm 1.74$ & \\
\hline 24 years and above & 18 & $110.77 \pm 1.63$ & \\
\hline \multicolumn{4}{|c|}{ Clinic the nurse currently works in } \\
\hline Emergency service & 53 & $108.26 \pm 1.40$ & \multirow{8}{*}{$\begin{array}{c}\mathrm{KWU}=38.62 \\
\mathrm{p}=0.00\end{array}$} \\
\hline Surgery room & 51 & $109.80 \pm 1.54$ & \\
\hline Eye- Otorhinolaryngology & 50 & $105.18 \pm 1.82$ & \\
\hline General surgery & 40 & $110.82 \pm 1.62$ & \\
\hline Neurosurgery & 37 & $113.81 \pm 1.34$ & \\
\hline Orthopedics & 33 & $103.00 \pm 2.19$ & \\
\hline Urology & 32 & $106.03 \pm 2.20$ & \\
\hline Cardiovascular- thoracic surgery & 28 & $107.50 \pm 2.15$ & \\
\hline
\end{tabular}

\begin{tabular}{|c|c|c|c|}
\hline Pediatric surgery & 20 & $117.20 \pm 1.63$ & \\
\hline Plastic surgery & 16 & $107.81 \pm 1.58$ & \\
\hline \multicolumn{4}{|l|}{ Number of injuries per year } \\
\hline No injury & 160 & $110.43 \pm 0.84$ & \multirow{4}{*}{$\begin{array}{c}\mathrm{KWU}=9.78 \\
\mathrm{p}=0.02\end{array}$} \\
\hline $1-5$ time $(s)$ & 166 & $106.95 \pm 0.90$ & \\
\hline 6- - 11 times & 15 & $111.73 \pm 2.36$ & \\
\hline 12 times and above & 19 & $106.00 \pm 2.82$ & \\
\hline \multicolumn{4}{|l|}{ Infection Control Committee } \\
\hline $\begin{array}{l}\text { I have knowledge about } \\
\text { their practices }\end{array}$ & 227 & $109.45 \pm 10.87$ & \multirow{2}{*}{$\begin{array}{l}t=1.79 \\
p=0.18\end{array}$} \\
\hline $\begin{array}{l}\text { I do not have knowledge about } \\
\text { their practices }\end{array}$ & & $107.27 \pm 11.94$ & \\
\hline \multicolumn{4}{|c|}{$\begin{array}{l}\mathrm{X} \pm \mathrm{SS} \mathrm{S}^{*} \text { : mean scale score } \pm \text { standard deviation; AYBH: Ankara Yıldırım Beyazıt Training } \\
\text { and Research Hospital; EOUTFH: Eskişehir Osmangazi Medical Faculty Hospital; AUMRH: } \\
\text { University Medical Faculty Research Hospital } \\
\text { When mean scale scores of nurses were assessed (Table 4), it was determined that the } \\
\text { minimum score received from the scale was } 71 \text {, the maximum score was } 125 \text {, and the } \\
\text { mean score received from the scale was } 108.64 \pm 11.30 \text {. }\end{array}$} \\
\hline
\end{tabular}

Table 4. Mean scale scores of nurses

\begin{tabular}{|l|c|c|c|}
\hline $\begin{array}{l}\text { Total Scale } \\
\text { Score }\end{array}$ & $\begin{array}{c}\text { Min-Max. } \\
\text { Score Received } \\
\text { from Scale }\end{array}$ & $\begin{array}{c}\text { Mean Scores } \\
\text { Received } \\
\text { from Scale } \\
\text { X } \pm \text { SS }\end{array}$ & $\begin{array}{c}\text { Cronbach's } \\
\text { Alpha of the } \\
\text { Scale }\end{array}$ \\
\hline & $71-125$ & $108.64 \pm 11.30$ & 0.86 \\
\hline
\end{tabular}

events could be that the patient was not an at-risk case, the infected tool was not used on the patient, the nurse had immunity, the nurse was too busy, there was no need to interfere, and the reporting system was thought to be a waste of time. In this study, it was determined that $37 \%$ of nurses were not aware of the practices of the infection control committees of the institutions they work for (Table 1). In a study conducted with the purpose of providing a program for the avoidance of sharp and needlestick injuries and occupational safety, it was determined that $57 \%$ of medical personnel knew which unit they should report to in case of a sharp and needlestick injury (13). In a study conducted to investigate the frequency of occupational accidents among nurses working in a training hospital, when the reasons for not reporting occupational accidents were examined, the most common answers were found to be: not thinking that reporting would be important (27.3\%), absence of a procedure in the hospital to report occupational accidents (27.3\%), and not knowing that reporting the incident was required (24.2\%) (14).

In this study, the most common cause of sharp and needlestick injuries was injuries due to injector needles (40.6\%), and injuries caused by broken ampoule pieces ranked second (32.5\%), (Table 2).Injuries caused by injector needles among nurses constitute the most commonly encountered occupational injuries with a wide range from $60 \%-90 \%(12)$. In a study, it was reported that $51.9 \%$ of nurses were exposed to injury with a pointed tool and $80.4 \%$ of this contact happened through an injector (15). According to the literature, $32 \%$ of percutaneous injuries occur with single-use injectors, $19 \%$ with suture needles, and $12 \%$ with winged steel needles (8). Additionally, it could be asserted that not trying 
to insert injector caps after using injectors will decrease the rates of needlestick injuries.

Even though exposure to viral and contagious agents through sharp and needlestick injuries can often be avoided, it continues to be a serious problem (13). In this study, it was determined that the vaccination rates of nurses against exposure to viral and contagious agents are not at the desired level (54.4\%) and $18.6 \%$ of nurses were negligent about vaccination (Table 2 ). Since effective protection against viral diseases is vaccination, all medical personnel of institutions providing medical services should be included in vaccination programs. In addition, when it is considered that viral and contagious diseases are spread through blood and infections (in the literature) have been reported to be high as a result of injector needle injuries, the seriousness of the problem is emphasized.

Injuries of medical personnel can occur in every field of work (16). In this study, the mean score of the nurses working in surgical clinics using the "scale of medical staff's attitude regarding the safe use of sharps and needlestick" questionnaire was quite high (Table 4). When an interdisciplinary assessment was performed, it was determined that the mean scale scores of nurses working in pediatric surgery units were significantly higher. In a study conducted by Samancıoğlu (17), where they researched the injuries suffered by nurses working in intensive care units as a result of the use of sharps and needlestick, they reported that these nurses were exposed to a higher level of injury, especially while closing the cover of injectors compared to nurses working in the intensive care units in the internal diseases department. In a study conducted by Akgür (12), the knowledge levels of nurses working in surgical units regarding the use of sharps and needlestick were higher than the knowledge levels of nurses working in emergency units, pediatric departments, and internal disease units. This may be related to the fact that nurses working in surgical units encounter invasive and non-invasive interventions at any moment and they follow the operated patient very attentively in terms of the practices. In the study conducted by Özyiğit et al. (18) to examine the attitudes of healthcare personnel working at a training and research hospital regarding the safe use of sharps, it was found that the mean scores of nurses working in surgical clinics $(85.71 \pm 7.05)$ were higher than those working in internal clinics. In the study of Yıldız (19), it was determined that the mean score of healthcare personnel regarding the safe use of medical tools was $114.16 \pm 8.59$.The results of the present study are similar to results of Özyiğit et al. (18) and Yıldız (19).

Another factor related to protection against sharps and needlestick injuries is the educational levels of nurses. In this study, nurses with a bachelor's degree had significantly higher mean scores compared to nurses who only had high school and associate degrees (Table 3).In a study conducted by Akgür (12), it was similarly reported that nurses who received undergraduate education had higher knowledge levels in terms of the use of sharps. This may be related to the fact that the curriculum received by nurses during their undergraduate education has qualities to improve the professional knowledge and skills (12). Additionally, it could be asserted that professionalization, which could be taught by undergraduate education and gained from experience, could raise awareness concerning taking precautions against injuries. The mean scores obtained from female nurses regarding the safe use of medical tools were higher than male nurses (Table 3). In the study conducted by Yıldız (19) to examine the safe use of sharps by medical personnel, it was found that the mean scores of women were higher than those of men. Furthermore, high- er scores could be associated with the fact that women constituted the majority of the sample.

$46.1 \%$ of the nurses participating in the study were reported to be exposed to injuries caused by sharps and needlestick 1-5 time(s) a year (Table 1). In a study conducted by Altıok (20) on medical personnel taking charge in different healthcare services, they reported the injury rate for the last one year as $79.1 \%$; on the other hand, Incesu (13) reported that $57.8 \%$ of the medical personnel within the scope of their study were exposed to injuries caused by sharps and needlestick 6-10 times. Aldem et al. (21) reported that the rate of medical personnel being exposed to sharp and needlestick injuries in the last year was $41.7 \%$ and $62.6 \%$ of the objects that caused injury were contaminated $(13,21)$. In a study conducted by Akgür (12), it was determined that $37.86 \%$ of nurses were exposed to sharp and needlestick injuries more than 7 times. The high rates of sharp and needlestick injuries among medical personnel and the objects contaminated with blood or body fluids lead us to believe that medical personnel are inadequately trained in terms of disposing sharps and are not taking universal safety precautions. This poses a large risk for the spreading of infectious diseases (21).

\section{Study limitations}

The results can be generalized only to the institutions of medical personel in which the study was conducted.

\section{Conclusion}

It could be asserted that the attitudes of surgical nurses regarding the safe use of sharps are at a good level. When it is considered that their rates of being exposed to sharp and needlestick injuries are high, the following can be recommended: routinely performing serologic tests, changing the submission of annual assessment reports into an institutional policy, determine the factors that cause sharp and needlestick injuries, offer in-service training programs periodically, make in-service trainings comprehensible and suitable to the trainee's level, ensure that precautions are correctly put into practice, and design and distribute informative warning components that specify what the personnel should do after injury and to which unit they should apply.

Ethics Committee Approval: Ethics committee approval was received for this study from the Ethics Committee of Atatürk University Institute of Health Sciences (12/03/2012).

Informed Consent: Written informed consent was obtained from patients who participated in this study.

Peer-review: Externally peer-reviewed.

Conflict of Interest: No conflict of interest was declared by the authors.

Financial Disclosure: The authors declared that this study has received no financial support.

\section{References}

1. Janowitz IL, Gille M, Ryan G, Rempel D, Trupin L, Swig L, et al. Measuring the physical demands of work in hospital setting: design and implementation of an ergonomics assessment. Appl Ergon 2006; 641-58. [CrossRef]

2. Kelly JE. Preventing Needlestick Injuries: Sharpen Your awareness. Notes on Nursing at Lahey Clinic 2004; 1-56. 
3. Korkmaz M. Needle-sticks in health care. Firat Journal of Health Services 2008; 3: 17-37.

4. Yenen \$O. The protection of the health staff of hospital-acquired infections. Current Medical Journal 2001; 6: 7-21.

5. Gammon J, Morgan-Samuel H, Gould DA. Review of the evidence for suboptimal compliance of healthcare practitioners to standard/universal infection control precautions. J Clin Nurs 2008; 17: 157-67.

6. Mollaoğlu M, Fertelli T, Tuncay ÖF. Evaluating perceptions of the work environment for nurses working in the hospital. Firat Journal of Health Services 2010; 5: 15-20.

7. Köşgeroğlu N, Ayrancı Ü, Bahar M. Nurses working in the operating room in cutting / piercing instrument and medical aid injuries received. 4. National Surgical and Operating Room Nursing Congress Book. Ege University Press, Izmir 2003; 295-304.

8. Doğan MY, Yaşar KM, Çırpı F, Bolca Z, Celayir AC. A state hospital epidemiology of needlestick injuries breaker- seen in 3 years and for protection measures. Zeynep Kamil Medical Bulletin 2009; 40: 11-5.

9. Nsubuga FM, Jaakkola MS. Needle stick injuries among nurses in sub-Saharan Africa. Trop Med Int Health 2005; 10: 773-81. [CrossRef]

10. Zafar A, Aslam N, Nasir N, Meraj R, Mehraj V. Knowledge, attitudes and practices of health care workers regarding needle stick injuries at a tertiary care hospital in Pakistan. J Pak Med Assoc 2008; 58: 57-60.

11. Uzunbayır N. Health penetrating medical devices for the safe use of employee attitude scale (dissertation). Medical Nursing, Ege University Institute of Health Sciences, 2009.

12. Akgür M. Knowledge and practices concerning nurses to medical stab wounds (dissertation). Institute of Health Sciences, Nursing Program, Yakın Doğu University, 2010.
13. Incesu E, Yorulmaz M, Doğrul M. Provision of Konya Seydişehir state prevent cutting and needlestick injuries in hospital programs and safety. 5th Health and Hospital Management Congress, 2011. Available from: http:// seydisehirdh.saglik.gov.tr/kalite/m9.pdf

14. Özarslan A. Training nurses working in hospitals in Ankara frequency of accidents at work (dissertation). Institute of Health Sciences, accidents Demography and Epidemiology Department, Gazi University, 2009.

15. Dokuzoğuz B. Transmitted infections and measures to contaminated medical instruments needlesticks. Journal of Hospital Infection 1999; 3 : 235-9.

16. Aygen B. Needlesticks injuries and infectious body fluids infected with the measures. ANKEM Derg 2003; 17: 157-63.

17. Samancıoğlu $S$, Ünlü $D, A$ kyol AD. Investigation of nurses working in intensive care situations stab wounds tool. Anatolian Journal of Nursing and Health Sciences 2013; 16: 43-9.

18. Özyiğit F, Küçük A, Arıkan I, Altuntaş Ö, Kumbasar H, Fener S, et al. The attitude of healthcare workers to safe use of medical instruments in a training and research hospital. Haseki Tıp Bülteni 2014; 168-71.

19. Yıldız, K. The evolution of the safe usage of sharp devices by the health care workers. Department of Internal Medicine, Nursing, Master's Thesis, Ege Univercity, 2011

20. Altıok M, Kuyurtar M, Karaçorlu S, Ersöz G, Erdoğan S. Health experience with stab injuries to employees and the measures taken to injury. Maltepe University Nursing Science and Art Journal 2009; 2: 70-9.

21. Aldem M, Arslan FT, Kurt AS. Employee safety and health professionals. Journal of Medical Research 2013; 11: 60-7. 